\title{
Notícias digitais como formas de conhecimento: um novo capítulo na Sociologia do Conhecimento ${ }^{1}$
}

\section{Rasmus Kleis Nielsen}

Universidade de Oxford, Oxford, Inglaterra

ORCID: https://orcid.org/0000-0002-3376-4918

\section{Tradução: Marcia Benetti}

Universidade Federal do Rio Grande do Sul, Programa de Pós-Graduação em Comunicação , Porto Alegre, RS, Brasil

ORCID: https://orcid.org/0000-0002-1621-8421

Anelise Schütz Dias

Universidade Federal do Rio Grande do Sul, Programa de Pós-Graduação em Comunicação, Porto Alegre, RS, Brasil

ORCID: https://orcid.org/0000-0003-4393-0702

\section{Marília Gehrke}

Universidade Federal do Rio Grande do Sul, Programa de Pós-Graduação em Comunicação, Porto Alegre, RS, Brasil

ORCID: https://orcid.org/0000-0003-3538-1600

\section{Resumo}

Este texto, publicado originalmente como capítulo de livro, discute as formas de conhecimento geradas pelas notícias digitais e é uma atualização do que Robert Park propõe no artigo A notícia como forma de conhecimento (News as a form of knowledge), de 1940. Park (1940) situou o jornalismo informativo em algum lugar do continuum entre a familiaridade com e o conhecimento sobre, e esta pesquisa avança ao oferecer três tipos ideais que caracterizam as notícias produzidas e consumidas em ambientes digitais: notícias-comoimpressões, notícias-como-itens e notícias-sobre-relações. Essas categorias são propostas e utilizadas para descrever e compreender o caráter mais efêmero ou mais contextual da notícia. $O$ texto defende, por fim, que as notícias digitais não geram apenas uma forma, mas formas de conhecimento.

\footnotetext{
${ }^{1}$ Do original: NIELSEN, Rasmus Kleis. Digital news as forms of knowledge: a new chapter in the Sociology of Knowledge. In: BOCZKOWSKI, Pablo; ANDERSON, C. W. (ed.). Remaking the news: essays on the future of journalism scholarship in the digital age. Cambridge: MIT Press, 2017. Direitos de tradução cedidos pela editora.
} 


\section{Palavras-chave}

Jornalismo. Jornalismo digital. Notícia. Sociologia do Conhecimento. Robert Park.

\section{Introdução}

As notícias estão intimamente relacionadas ao conhecimento. É parte da autocompreensão do jornalismo que as notícias ajudam as pessoas a entender o mundo ao seu redor. Querer saber mais sobre o mundo é uma motivação-chave para o uso de notícias. A hipótese de que aqueles que consomem notícias sabem, de fato, mais sobre o mundo ao seu redor tem sido um foco central da análise acadêmica sobre esse tema. A ideia de que as notícias levam a uma cidadania mais informada e capacitada e, portanto, a uma sociedade mais funcional e a uma democracia mais robusta tem sido fundamental para a maioria das teorias normativas do jornalismo. Todos esses diferentes autoentendimentos, motivações pessoais, hipóteses acadêmicas e teorias normativas baseiam-se na conexão entre a notícia e o conhecimento.

Que tipos de conhecimento, então, as notícias geram? E como as notícias, enquanto conhecimento, mudam de acordo com as práticas sociais, formas organizacionais, tecnologias de mídia que criam e constituem essas mudanças ao longo do tempo? 0 ensaio de Robert E. Park, de 1940, A notícia como forma de conhecimento: um capítulo na Sociologia do Conhecimento, continua a ser o tratamento seminal da questão - uma análise sociológica profunda, focada não simplesmente na informação contida em notícias individuais ou no impacto que tais informações podem ter sobre os usuários de mídia, mas no significado da categoria mais ampla de notícia e seus aspectos sociais, organizacionais e tecnológicos.

Park estava, de certa forma, singularmente bem posicionado para escrever sobre esse assunto - antes de seu pioneirismo como um dos fundadores da Escola de Sociologia de Chicago, atuou tanto como jornalista quanto como publicitário. Além disso, trabalhou como pesquisador para o educador e ativista político afro-americano Booker T. Washington no Instituto Tuskegee. Park era um homem mais do que conectado à pesquisa acadêmica e à prática profissional: tinha uma preocupação duradoura sobre como o conhecimento é produzido, reconhecido como tal e posto em circulação e sobre como orienta, envolve e une comunidades de diferentes formas. 
Este texto pretende abordar que tipos de conhecimento as notícias digitais podem gerar e pretende oferecer uma continuação contemporânea para o que Park chamou de "um capítulo na Sociologia do Conhecimento". Considero este um campo focado não na epistemologia do jornalismo ou na validade do conhecimento dos jornalistas, mas nas condições existentes sob as quais surgem diferentes tipos de conhecimento ${ }^{2}$. Estou interessado pelo que muda no conteúdo, na produção e na disseminação de notícias, bem como na organização do trabalho jornalístico, e o que isso significa para a notícia como conhecimento. Discutirei essas questões a partir de exemplos do passado e do presente dos Estados Unidos. Na primeira parte do texto, retorno para os Estados Unidos de 1940 e para a análise original de Park sobre as notícias como forma de conhecimento, que estariam posicionadas entre o conhecimento formal e sistemático, conhecimento sobre [knowledge about] e o mais intuitivo e não sistemático, familiaridade com [acquaintance with]. Na segunda parte, desenvolvo uma análise das notícias digitais como forma de conhecimento em diferentes tipos de ambientes midiáticos dos Estados Unidos em 2015. Na terceira e última parte, discuto as implicações amplas das notícias digitais como um novo capítulo da Sociologia do Conhecimento.

No geral, meu argumento é que, embora Park pudesse oferecer um tipo ideal plausível para entender as notícias como uma forma de conhecimento em 1940, essa visão unitária é menos útil 75 anos mais tarde. Por isso, devemos diversificar cada vez mais nossas análises na tentativa de entender as notícias na atualidade. A notícia é um fenômeno histórico e sua forma tem mudado ao longo do tempo e do espaço (BARNHURST; MUTZ, 1997). Sugiro que muitas notícias, ainda hoje, são frequentemente caracterizadas por muitos dos traços identificados por Park (1940), mas nosso ambiente de mídia, cada vez mais digital, oferece formas mais diversas de notícias. Além disso, o ambiente digital inclui uma quantidade crescente de tipos de notícias substancialmente mais próximas dos extremos formulados por William James (1890) de familiaridade com e conhecimento sobre. Hoje percebemos, simultaneamente, tanto uma ênfase cada vez maior no imediato, nas notícias de última hora, no minuto a minuto e no segundo a segundo, quanto a expansão de novas formas de jornalismo criadas para superar algumas das deficiências epistemológicas percebidas nas formas antigas de notícias, a exemplo dos jornalismos long-

\footnotetext{
${ }^{2}$ A epistemologia do jornalismo tem recebido atenção de autores como Tuchman e Glasser (1978), Ettema e Glaser (1998). A validação do jornalismo é um tema cada vez mais abordado na cobertura metajornalística, a exemplo das organizações de fact-checking (GRAVES, 2016).
} 
form $^{3}$, explicativo e de dados. Essas são novas formas de notícias como conhecimento, que têm se afirmado por seu conteúdo e também pelo uso de certas affordances das mídias digitais.

A partir de Park (1940) e de sua inspiração por James (1890), sugiro que possamos pensar as notícias digitais a partir de pelo menos três diferentes tipos ideais de formas de conhecimento público e mediado. Primeiro, nós vemos a crescente importância das formas de notícias-como-impressões - fragmentos descontextualizados de informação apresentados via serviços de manchetes, de alertas de notícias e de live tickers e também por meio de uma variedade de novos intermediários digitais, o que inclui ferramentas de busca, mídias sociais e aplicativos de mensagens. Em segundo lugar, permanece importante um descendente reconhecível da forma arquetípica de notícias do final do século XX: notíciascomo-itens - artigos individuais ou histórias agrupadas em jornal, rádio, TV, site ou aplicativo. Em terceiro lugar, no extremo oposto do espectro de James (1890), da familiaridade com para o conhecimento sobre, vemos o surgimento de notícias-sobrerelações - elas apresentam elementos contextuais do jornalismo long-form ou formas explicativas de jornalismo bem conhecidas de alguns dos jornais, revistas e programas de atualidades do século XX (FINK; SCHUDSON, 2014).

As notícias digitais podem estar associadas à ascensão das notícias-comoimpressões e a um potencial esvaziamento de formas herdadas das notícias-como-itens, que contêm informações transitórias e perecíveis, as quais Park (1940, p. 676) classificou como integrantes de um "presente ilusório". Muitos críticos, entre jornalistas, acadêmicos e outras figuras públicas, queixam-se das qualidades associadas ao churnalism ${ }^{4}$ das notícias digitais. Entretanto, a notícia digital é muito mais do que isso e devemos suspeitar de generalizações sobre sua natureza. Também é preciso considerar que elas envolvem um notável crescimento das notícias-sobre-relações, mais orientadas para fornecer o que James (1890) chamou de conhecimento sobre. A notícia de hoje é provavelmente mais acessível, oportuna, detalhada e orientada por dados do que nunca.

Reconhecer as propriedades das notícias digitais - as diferentes formas de conhecimento, em vez de a forma de conhecimento - ajudará a compreender como os

\footnotetext{
${ }^{3}$ Nota das tradutoras: o termo long-form não costuma ser traduzido no Brasil. De acordo com Longhi e Winques (2015), tratase de uma narrativa longa e aprofundada, voltada à publicação online.

${ }^{4}$ Nota das tradutoras: churnalism é um termo pejorativo utilizado para designar o jornalismo feito principalmente com base em releases, conteúdos produzidos por agências e a partir da reutilização de materiais já existentes, sem apuração própria e trabalho de investigação. 0 principal propósito é reduzir custos no trabalho de busca e checagem das informações. Publicações online são terreno fértil para esse tipo de jornalismo. 0 termo se espalhou principalmente entre os britânicos em 2015 e sua criação é atribuída ao jornalista Waseem Zakir, da BBC.
} 
autoentendimentos, as concepções, as hipóteses acadêmicas e as teorias normativas de jornalismo podem exigir que se repense a conexão básica entre a notícia e o conhecimento, já que todos esses aspectos estão sujeitos a mudanças ao longo do tempo.

\section{Notícia como forma de conhecimento}

Em sua pesquisa original sobre a notícia como forma de conhecimento, Park (1940) estava interessado em entendê-la como fenômeno mediado e disponível publicamente, como ocorre no jornalismo informativo. Pode-se traçar a distinção entre notícias nesse sentido mais restrito de informação que é publicada ou transmitida e é de registro público e notícias no sentido mais amplo de novidades.

A notícia, no primeiro sentido, está profundamente interligada com um grande espectro de outras formas de comunicação social, que incluem rumores, fofocas e conversas interpessoais - a notícia como aquilo que faz as pessoas falarem (SHIBUTANI, 1960). No entanto, as notícias são de outra natureza, por seu caráter público e mediado e porque a categoria notícia é vista como significante e distinta. Partindo da tradição sociológica do desenvolvimento de tipos ideais - construções conceituais formuladas indutivamente pela acentuação de uma ou mais características de uma classe de fenômenos para permitir a categorização e a generalização analítica -, a pesquisa de Park (1940) objetiva identificar as propriedades compartilhadas pelo tipo de notícia que associamos especificamente com o jornalismo, para então ser possível acessar o tipo de conhecimento que a notícia representa.

A análise de Park (1940) sobre as notícias como forma de conhecimento começa com a distinção entre familiaridade com e conhecimento sobre desenvolvida pelo filósofo e psicólogo William James (1890) em Princípios da Psicologia. No trabalho de James (1890), a familiaridade com é um conhecimento mais informal, intuitivo e não sistemático, e o conhecimento sobre é relativamente mais formal, teórico e sistemático. A familiaridade com vem com o uso e com o hábito e é frequentemente baseada na experiência em primeira mão.

O conhecimento sobre vem com investigação sistemática, é ativamente adquirido e, frequentemente, obtido por meio de fontes secundárias. Segundo James (1890, p. 221):

Existem dois tipos de conhecimento ampla e praticamente distinguíveis: podemos chamá-los, respectivamente, de "knowledge of acquaintance" [conhecimento por familiaridade] e "knowledge about" [conhecimento sobre]. A maioria das línguas expressam essa distinção: assim, $\gamma v \omega ́ v \alpha \iota / \varepsilon l$ Io $\mu \alpha \iota$; noscere/scire; kennen/wissen; connaître/savoir. Eu estou 
familiarizado com muitas pessoas e coisas, sobre as quais sei muito pouco, exceto a presença delas em lugares em que eu as tinha encontrado. Eu reconheço a cor azul quando a vejo e o sabor da pera quando a provo; eu reconheço uma polegada quando movo meu dedo; um segundo de tempo, quando o sinto passar; um esforço de atenção quando o faço; a diferença entre duas coisas quando a percebo; mas sobre a natureza íntima desses fatos e o que faz deles o que são, eu não posso dizer nada. [...] Mas, em geral, quanto menos analisamos uma coisa e quanto menos percebemos as relações dessa coisa, menos nós sabemos sobre ela e mais nossa familiaridade é do tipo "acquaintance". Os dois tipos de conhecimento são, assim, como a mente humana os exerce na prática, termos relativos. Isto é, o mesmo pensamento sobre a coisa pode ser chamado de conhecimento sobre ela, em comparação com um pensamento mais simples ou de "familiaridade com". [...] Aquilo com que temos somente "familiaridade" está apenas presente em nossas mentes; nós temos isso ou a ideia disso. Mas, quando nós tomamos conhecimento sobre essa coisa, nós fazemos mais do que meramente tê-la; parece que, ao pensarmos sobre suas relações, nós a submetemos a um tipo de tratamento e nela operamos com nosso pensamento [...]. 0 "conhecimento sobre" trata do conhecimento de uma coisa e suas relações. A "familiaridade com" é limitada à mera impressão que essa coisa produz.

Para Park (1940), assim como para James (1890), a distinção não implica uma hierarquia, mas reflete diferentes formas de adquirir conhecimento e modos de esse conhecimento desempenhar diferentes papéis na vida das pessoas. Conhecimento tácito e experiência prática no final do espectro da familiaridade com são frequentemente formas melhores de saber como fazer algo ou de conhecer outra pessoa do que o conhecimento sobre. Algumas formas mais sistemáticas de conhecimento, porém, são superiores no tratamento de doenças sérias ou no entendimento das causas de uma crise financeira global, bem como de suas consequências. Saber que há tropas russas na Ucrânia, por exemplo, é do domínio das impressões; saber por que elas estão lá ou o que isso deve significar diz respeito às relações.

0 argumento básico de Park (1940) é que, se alguém pensar a familiaridade com e o conhecimento sobre de James (1890) como num continuum "[...] no qual todos os tipos e classificações de conhecimento encontram um lugar", então as notícias têm sua própria localização entre os dois extremos (PARK, 1940, p. 675). É importante recapitular o que Park (1940) vê como os traços definidores da notícia, uma vez que isso continua instantaneamente reconhecível e relevante 75 anos depois - apesar de a análise histórica sugerir que a notícia nos Estados Unidos, como um todo, cresceu muito, tornando-se mais analítica e mais abstrata (BARNHURST; MUTZ, 1997). 
A notícia é uma forma de conhecimento, de acordo com Park (1940), mais formal e sistemática do que a familiaridade com e oferece às pessoas conhecimento sobre o mundo além do que se pode adquirir com a experiência pessoal, porque é comunicável e comunicada de um modo que o conhecimento tácito não é. Porém, não se trata do mesmo que o conhecimento sobre, pois permanece focada em eventos mais do que em processos, em relações entre eventos e em suas causas ou significados. Nesse sentido, a notícia é muito mais os quatro primeiros "Ws" dos famosos cinco "Ws" jornalísticos - ela oferece mais o que aconteceu [what], quem fez [who], quando [when] e onde [where] do que o quinto "W", o porquê [why].

Ao longo de sua pesquisa, Park (1940) defende que as notícias são orientadas para os eventos e interessadas no passado e no futuro, assim como na causalidade e na teleologia, apenas na medida em que essas relações podem jogar luz na atualidade e no presente (comentários e opiniões são uma variação disso, talvez menos fortes em informar as pessoas sobre eventos e mais orientados para interpretar ou afirmar causalidade e teleologia). Em outro apontamento, que ainda é lugar-comum hoje, Park (1940) argumenta que as notícias existem apenas no que ele chama de "presente ilusório". "Presente" porque se trata do agora (hoje aqui, amanhã já se foi, primeiro rascunho da história etc.) e "ilusório" porque o que as qualifica como notícias do presente é determinado não simplesmente pela atualidade, que por si só tem uma importância intrínseca, mas pelas considerações dos jornalistas sobre notícias, rotinas organizacionais, publicidade e outros interesses. A notícia também é definida pela variação das concepções sobre aquilo em que as pessoas estão interessadas. Essa combinação leva a notícia a focar no oficial, no excitante, no incomum e no inesperado (apesar de, é claro, muito do presente atual ser muito mais humilde, mundano, comum e esperado). O foco nos eventos e no presente, na visão de Park (1940), torna a notícia "transitória e efêmera", um constante fluxo de pequenas e independentes comunicações que podem ser fácil e rapidamente compreendidas por pessoas que, por consumirem notícias, podem se orientar em um mundo mais vasto do que a sua experiência pessoal. Ainda assim, essas pessoas continuam a depender de outras formas de conhecimento, mais próximas dos extremos da familiaridade com e do conhecimento sobre, quando se trata de navegar no cotidiano da vida e do trabalho. As notícias, nesse sentido, nos ajudam a nos orientar no mundo, especialmente no que está além da nossa experiência pessoal e profissional (PARK, 1940), mesmo que não necessariamente cultivem uma familiaridade com ou um 
conhecimento sobre. Ter lido sobre as tropas russas na Ucrânia é diferente de tê-las visto no jardim ou de estar a par de seus planos e finalidades.

A descrição de Park (1940) da notícia como caracterizada (1) por uma orientação para os eventos mais do que para os processos, (2) pela pequena discussão de causalidade ou teleologia e (3) por sua natureza transitória e efêmera é uma descrição reconhecível e relevante 75 anos mais tarde, ainda que sua análise tenha sido construída a partir de um ambiente midiático muito diferente do de hoje. Os Estados Unidos, em 1940, tinham um sistema pesadamente regionalizado, com pouco em termos de uma mídia verdadeiramente nacional (muito menos de uma mídia internacional), e em que as notícias eram primariamente mediadas pelos jornais e pelo rádio (e, até certo ponto, pelas revistas e noticiários). As tecnologias midiáticas mais comuns do tempo de Park são encarnações materiais do que ele afirmava sobre a transitoriedade e a efemeridade das notícias. Havia jornais diários, frequentemente ultrapassados por eventos e transmissões radiofônicas que se dissipavam no ar. A indústria do jornal que sobreviveu à Grande Depressão era vibrante, com alta circulação. A maior parte do país era coberta por jornais locais, e as grandes áreas metropolitanas sustentavam uma série de títulos, que competiam da manhã à noite e que eram de diferentes orientações e convicções políticas. Em Chicago, isso incluía não apenas o Tribune, mas também outros diários como o Daily News, o Times e o Sun, e o mais proeminente jornal afro-americano do país, o Chicago Defender. Também havia uma gama de outros semanários, jornais comunitários, jornais de subúrbio e títulos em outras línguas.

0 rádio, em 1940, chegava a $80 \%$ das residências, mas não seguia mais o modelo informal e para todos dos anos de 1920. Os anos de 1930 viram a transformação do que costumava ser um grande número de torres de transmissão separadas - de transmissão independente, por diferentes razões, que competiam por atenção com muitas outras - em um negócio mais consolidado e comercial, dominado por poucas e grandes redes, que ligavam um grande número de estações através do país (BARNOUW, 1968).

Esse ambiente midiático era definitivamente de comunicação de massa em termos de uma larga audiência de usuários de mídia. Contudo, esse não é o tipo de ambiente midiático mais nacionalmente orientado, característico do rádio pós-guerra e da transmissão televisiva. Em 1940, as famosas "conversas ao pé da lareira" ${ }^{5}$ de Franklin D.

\footnotetext{
5 Nota das tradutoras: “Conversas ao pé da lareira” foi uma série de programas de rádio conduzida pelo presidente Franklin D. Roosevelt entre 1933 e 1944 e costumava ir ao ar no fim da tarde. Era o modo como o presidente se comunicava com a população de milhões de estadunidenses sobre questões ligadas ao governo, incluindo a Segunda Guerra Mundial. No rádio, ele desmentia rumores e explicava as políticas públicas.
} 
Roosevelt alcançavam uma estimativa de $25 \%$ da audiência do rádio, e cerca da metade dela se estabeleceria na televisão nas décadas de 1960 e 1970 (CRAIG, 2000; ESHBAUG-SOHA; PEAKE, 2011). É preciso considerar que esse ambiente é desprovido de duas das mais importantes plataformas midiáticas de notícias de hoje - a televisão e a internet - e que a mídia, à época, ocupava uma parte mais restrita da vida cotidiana da maioria das pessoas do que atualmente.

\section{As notícias digitais como formas de conhecimento}

Hoje, nosso ambiente de mídia é marcadamente diferente. Em 2015, os Estados Unidos ainda tinham uma estrutura de mídia regional composta por mais de 16.000 estações de rádio, mais de 2.000 emissoras de televisão e mais de 1.300 jornais diários, assim como milhares de sites de notícia sobre diversos assuntos ${ }^{6}$. É um mercado em que a imprensa local e regional ainda é importante para a formação de repertório do público, mas há também uma variação de veículos de mídia nacional, principalmente de redes jornalísticas de televisão, canais de TV a cabo que cobrem notícias e sites de um pequeno número de jornais de referência, como o The New York Times, e jornais digitais, como o Huffington Post. Enquanto em 1940, nos Estados Unidos, havia muita mídia local e pouca mídia nacional, a situação em 2015 corresponde ao aumento da mídia nacional e a menos mídia local. Trata-se, hoje, de um ambiente de mídia digital em crescimento (mesmo que a TV ainda corresponda à maior parte do tempo gasto pelo público), cada vez mais acessado via internet e explorado por meio de sites, mecanismos de busca e mídias sociais. Este é, portanto, um ambiente caracterizado por audiências de massa, se considerarmos que massa pode significar um grande número de indivíduos engajados com o mesmo conteúdo. Assim como na época de Park, não se trata de um ambiente de audiência nacional massiva, como ocorreu nas décadas de 1970 e 1980.

O pronunciamento público do presidente Barack Obama, em 2015, atraiu mais de 30 milhões de espectadores e uma cota de audiência combinada de 20\%, através de 13 canais de televisão. Esses números não estavam distantes da audiência de Roosevelt em suas "conversas ao pé da lareira", mas estavam consideravelmente abaixo dos 67 milhões de espectadores e dos $44 \%$ de audiência de quando o presidente Bill Clinton realizou seu

\footnotetext{
6 Dados do Federal Communications Commission, do News Media Alliance, e do boletim do Estado da Mídia do Projeto para a Excelência do Jornalismo em 2014 (MITCHELL; PAGE, 2014).
} 
primeiro pronunciamento oficial em janeiro de 1993 (NIELSEN SOCIAL, 2015). Eventos de mídia como o Super Bowl e os Jogos Olímpicos ainda podem captar um grande público, mas o consumo de notícias no dia a dia é caracterizado pela fragmentação e duplicação da audiência, em vez de grandes audiências esporádicas em poucos eventos veiculados pela mídia (WEBSTER, 2014). É um ambiente em que o legado da mídia, anterior à ascensão digital, continua sendo importante para a maior parte das pessoas, mas também em que os modelos de negócio têm sido profundamente disruptivos, com a migração de anúncios para plataformas digitais e a constante disputa pela atenção da audiência. Trata-se de um ambiente em que as duas plataformas de mídia mais importantes para notícias são a televisão e a internet (NEWMAN, 2015), mas ambas, é claro, são muito diferentes da mídia da época de Park.

Estudiosos e comentaristas investiram em certa visão de que as notícias podem ou deveriam ser altamente mais críticas do que o que a televisão e o meio digital oferecem hoje. Resumindo brevemente, muitos argumentam que o aumento das pressões comerciais e a intensificação da disputa por audiência levam a um cenário de infotenimento, de conteúdo mais opinativo e de mais sensacionalismo (FENTON, 2010). James Fallows (2011) jornalista, escritor e antigo responsável pelos discursos do ex-presidente Jimmy Carter avalia as notícias digitais como rasas, fragmentadas e não confiáveis (no Reino Unido, a tendência tem sido resumida como uma mudança do jornalismo para o churnalism). Barack Obama parece concordar com a avaliação. Em 2010, quando questionado por um estudante da Universidade de George Washington sobre o que mais o surpreendeu à frente do governo, o então presidente respondeu:

\footnotetext{
Bem, por onde eu começo? (Risos). Por um lado, eu tenho me surpreendido em como o ciclo de notícias de Washington está focado no que acontece neste minuto em vez de ao longo dos meses e anos. 0 ciclo de notícias de 24 horas é tão rápido, e sua atenção é tão voltada para um período tão curto, que às vezes é difícil manter todo mundo focado em longo prazo. 0 que realmente importará em termos de sucesso da América em 20 anos não são as coisas que vêm sendo discutidas na televisão em qualquer dia ou que surgem na internet em um blog em um determinado dia (OBAMA, 2010, s.p.).
}

A acusação dos acadêmicos, comentaristas e figuras públicas parece clara. Veículos de comunicação foram, inicialmente, lentos na reinvenção das formas da notícia e na adaptação ao ambiente digital, optando por apenas transferir o conteúdo analógico para as 
formas digitais como shovelware ${ }^{7}$. Agora, porém, novas formas genuinamente digitais estão sendo desenvolvidas e muitos críticos não estão surpresos. Se tradicionalmente a intenção do jornalismo era informar as pessoas fazendo com que o significante fosse interessante e o interessante fosse significante, a acusação de hoje é que, considerando as pressões comerciais e competitivas permeadas pela tecnologia, há um foco crescente em tornar o interessante tão interessante quanto possível em busca de atenção, deixando o que é significante de lado. A acusação, resumidamente, é que as notícias de 2015 são semelhantes às que Park descreveu em 1940, mas ainda mais focadas em eventos, mais restritas às discussões de causalidade e teleologia (mesmo que oferecendo provavelmente mais comentários e análises, alguns mais opinativos e especulativos, como sempre) e ainda mais transitórias e efêmeras. Em sua melhor forma epistemológica, essas notícias podem oferecer uma forma mediada, de segunda mão, da familiaridade com (isso, aquilo e aquilo outro aconteceram). Em sua pior forma, pode fazer sentido pensar não em conhecimento de maneira geral, mas apenas em uma grande quantidade de impressões - muito barulho, sem sinal (GITLIN, 2001).

Conforme dito anteriormente, penso que os críticos estão parcialmente certos, mas também penso que a acusação está incorreta se confundirmos o que podem ser formas de notícias contemporâneas com algo mais amplo, mais variado e mais abundante. Ainda que reconhecendo as diferenças entre jornais, rádios, noticiários de televisão e revistas, Park poderia plausivelmente oferecer uma análise da notícia como uma forma de conhecimento, posicionada entre a familiaridade com e o conhecimento sobre em 1940. Seu tipo ideal nunca correspondeu a todas as notícias, mas capturou aspectos-chave da maior parte delas e de suas formas mais importantes. Porém, uma visão única é menos útil em 2015, em que temos visto a intensificação de algumas características pontuadas por Park (1940) que partem das notícias de última hora [breaking news] e das notícias leves [soft/light news] em direção a uma versão de familiaridade com do espectro de William James (1890). Em paralelo e de forma igualmente importante, está o desenvolvimento de formas de notícias mais próximas do conhecimento sobre, no fim do continuum de James, em que ainda há muitas notícias mediadas, publicamente disponíveis e muito mais oportunas que outras formas de conhecimento sobre (como aquelas oferecidas pelos cientistas). As notícias digitais são as

\footnotetext{
7 Nota das tradutoras: este termo não tem tradução literal para o português e significa algo como "passar de um dispositivo para outro sem alterações no conteúdo". No Brasil, a pesquisadora Luciana Mielniczuk $(2003$, p. 32) definiu a prática como "transposição de conteúdos", o que caracterizava o Webjornalismo de Primeira Geração (ou fase da transposição), quando os primeiros jornais impressos passaram a disponibilizar seus conteúdos na Web, nos primeiros anos da década de 1990. Nesta fase, explica a autora, quase que a totalidade do material oferecido na Web era cópia da versão impressa.
} 
atualizações no Twitter, blogging ao vivo e cobertura de eventos de última hora pela TV, às vezes em espaços onde parece não haver conhecimento. As notícias digitais também podem ser jornalismo long-form, em profundidade, detalhadas, de interações guiadas por dados, de streaming sob demanda ou de download de assuntos atuais ou, ainda, de documentários. Diante disso, precisamos de mais tipos ideais para capturar o aumento da diversidade dessas formas de notícias e deveríamos ser céticos quanto às análises e aos comentários que capturam apenas uma tendência geral comum a todas as formas de notícia.

Na familiaridade com do início do continuum de James (1890), vemos a importância crescente de formas de notícias que são relatos cada vez mais sistemáticos de que, quem, quando e onde, com menos espaço para os porquês. Uma publicação no Facebook, uma postagem de 140 caracteres no Twitter8, um alerta de notícia no celular ou no relógio [smartwatch] ou um vídeo de 57 segundos compartilhado no Instagram fornecerão algum tipo de impressão e talvez alguma informação, mas não tratarão muito sobre relações, causas ou teleologia, não importa quão consciente, séria e importante for a organização jornalística. Na televisão, os canais com 24 horas de notícias podem ser um exemplo claro disso, já que eles não se encaixam no modelo de não ter tempo ou espaço para uma determinada cobertura (são canais 24 horas, afinal), mas são estruturados sob um formato em que o imperativo do ao vivo e das notícias de última hora frequentemente leva a situações em que parece importante questionar o valor do negócio como um todo, ao menos em termos de conhecimento. Podemos citar dois casos da CNN, uma organização indiscutivelmente mais comprometida com formas tradicionais de jornalismo do que outras empresas de televisão a cabo. Em 28 de junho de 2012, a CNN divulgou "Mandado derrubado" no ar, no seu site e no Twitter, com a linha de apoio "Suprema Corte considera medida inconstitucional", sugerindo, equivocadamente, que a Corte havia decidido contra o Ato de Cuidado Acessível (Affordable Care Act, também conhecido como Obamacare). Na verdade, a Suprema Corte tinha mantido o ato por 5 a 4. Em 18 de abril de 2013, após o atentado à Maratona de Boston e enquanto a caçada aos criminosos ainda estava acontecendo, a CNN reportou erroneamente que um suspeito havia sido preso. Ambos são acontecimentos importantes em que a audiência da TV a cabo dispara. E ambos são casos importantes e sérios em termos de erro jornalístico.

As notícias de última hora na televisão não oferecem, sozinhas, um fluxo constante de notícias como conteúdo. São exemplos disso feeds de notícia e sites constantemente

\footnotetext{
${ }^{8}$ Nota das tradutoras: hoje são 280 caracteres.
} 
atualizados, assim como blogs dedicados à cobertura ao vivo em torno de acontecimentos importantes como pronunciamentos políticos, lançamento de produtos ou eventos esportivos. Também serve de exemplo a distribuição via sites de redes sociais de terceiros, o que pode incluir tanto o Facebook e o Twitter quanto o Instagram e o Snapchat. Alf Hermida (2010) criou a expressão "notícias de ambiente" (ambient news) para descrever como plataformas de micro-blogging, a exemplo do Twitter, podem funcionar como um "sistema de monitoramento" (awareness system) que oferece disseminação online instantânea de fragmentos de informação a partir de fontes variadas. Isso é parte do que os profissionais da indústria da mídia veem como um fenômeno mais amplo, em que a informação digital é, nas palavras de Eric Schonfeld (2009), "Cada vez mais distribuída e apresentada em fluxo de tempo real em vez de em páginas na Web dedicadas a isso.". Trata-se de uma organização pela Web, como as notícias de última hora na televisão, em uma cronologia reversa baseada no agora e em um permanente fluxo de informação. Vemos isso em sites de redes sociais, como o Facebook e especialmente o Twitter, no modo como as organizações jornalísticas usam seus sites para distribuir o fluxo de seu próprio conteúdo - segundo Thompson (2015), estima-se que, em média, 1\% dos usuários clicam nos links indicados - e em iniciativas digitais que variam do Buzzfeed ao Times Wire (MADRIGAL, 2013). Esse fluxo de conteúdo é o tipo de fenômeno que muitos acadêmicos, comentaristas e figuras públicas desacreditam. Ainda são notícias, dado que são produzidas por jornalistas e reivindicadas como tal, são mediadas e disponibilizadas publicamente, mas são de vários modos menos sistemáticas e mais próximas da noção de William James de familiaridade com do que as formas mais tradicionais que associamos a jornais e a boletins de televisão. São notícias mediadas, de segunda mão, que fornecem impressões, mas não estabelecem relações.

No entanto, esse tipo de notícia não é o único. Esse é um ponto simples, mas importante ${ }^{9}$. Hoje existem formas de notícia ainda mais mediadas e publicamente disponíveis próximas do conhecimento sobre do final do continuum de James. Enquanto a retração da indústria de notícias levou, de maneira geral, a um declínio dos repórteres especializados nas editorias, também temos visto, nas últimas décadas, a ascensão de vários modos de jornalismos long-form, explicativo e de dados, que são claramente diferentes das notícias imediatas e não sistemáticas oferecidas nos canais 24 horas e nos fluxos digitais. Elas também são diferentes das formas de notícia sobre as quais Park (1940) escreveu -

\footnotetext{
${ }^{9}$ Conforme notado por Herbert J. Gans (1974), críticos preocupados com o "emburrecimento" muitas vezes ignoram o processo paralelo de "geração de inteligência".
} 
Katherine Fink e Michael Schudson (2014) chamam esse fenômeno de "ascensão do jornalismo contextual". Tomemos como exemplo a investigação de Dana Priest e William Arkin (2011) sobre o "Grande Segredo da América” (Top Secret America) para o Washington Post. Trata-se de uma reportagem extensa sobre o crescimento da segurança nacional e dos serviços de inteligência após o 11 de Setembro. 0 projeto levou quase dois anos, envolveu outros 27 colaboradores e gerou a produção de uma série de reportagens. Resultou em um site com textos adicionais, vídeos, múltiplos gráficos interativos e bases de dados com mecanismos de busca e em um blog do projeto. Também deu origem a uma página no Facebook, a uma conta no Twitter, a um documentário Frontline de uma hora para a TV PBS (e uma continuação), assim como a um livro. 0 que quer que isso seja, não é familiaridade com, não é "churnalism", ainda que possa ter algumas deficiências como forma de conhecimento público e mediado.

Consideremos também o guia visual, atualmente ativo, do The New York Times para o conflito entre o Iraque e o Estado Islâmico, que traz uma atualização contínua e digital que combina reportagem convencional na área afetada pelo conflito (textos e fotos) com múltiplos mapas interativos, imagens de satélite dos rios Eufrates e Tigre, mapas dos ataques aéreos dos Estados Unidos, visualização de dados de onde os combatentes do Estado Islâmico vêm e mapas históricos da antiga área do Império Otomano. Trata-se de um trabalho de reportagem sistemático, principalmente orientado pelo quê, pelo quem, pelo quando e pelo onde, mas com muito mais atenção aos porquês e às consequências e com modos de narração que vão além das notícias individuais ou das séries com múltiplas partes que adotam novas formas de apresentação digital. Isso não é impressionista. Isso envolve relações, muito perto da visão de James do conhecimento sobre, e é muito mais oportuno do que o conhecimento sobre produzido por ONGs, think tanks e acadêmicos. A questão, aqui, não é que esse tipo de reportagem em profundidade seja intrinsecamente superior ao ambiente de notícias promovido pela TV a cabo e pelos feeds de notícias digitais. Também não é que seja perfeito - o jornalismo de dados, por exemplo, é altamente dependente de bases de dados que são difíceis de verificar e mesmo repórteres com muitos recursos cometem erros. A questão é: isso é simplesmente diferente, esses distintos tipos coexistem e ambos possuem características de notícias como diferentes formas de conhecimento.

Em uma posição às vezes invocada por profissionais da indústria quando falam sobre as notícias digitais, o autor americano Robin Sloan (2010, s.p.) sugere uma distinção 
entre a corrente de impressões (o que ele chama de "fluxo") e o "estoque" de coisas que duram mais e se destacam:

O fluxo é o feed. São as postagens e os tuítes. É a corrente de atualizações diárias e subdiárias que lembram as pessoas de que você existe. 0 estoque são as coisas duráveis. É o conteúdo produzido que se mantém interessante em dois meses (ou dois anos) assim como hoje. É o que as pessoas descobrem por meio das buscas. É o que se espalha devagar, mas com certeza se espalha, conquistando fãs ao longo do tempo.

Em 1940, Park argumentou que a notícia como forma de conhecimento está posicionada entre os extremos do continuum de William James. Está entre a familiaridade com intuitiva e não sistemática e o mais formal e sistemático conhecimento sobre, como uma forma de conhecimento mediada, publicamente disponível e caracterizada: (1) pela orientação para os eventos, em detrimento dos processos; (2) pela pouca discussão de causalidade ou teleologia, e (3) por uma natureza transitória e efêmera. Muito disso ainda é verdadeiro. No entanto, a visão unitária que ele ofereceu é cada vez menos útil quando se trata de notícias digitais. A utilidade intelectual dos tipos ideais é que eles nos ajudam a entender os aspectos mais importantes da realidade, e um único tipo ideal já não é adequado para capturar um fenômeno crescente e cada vez mais variado. Uma parte significativa das notícias é, como muitos têm argumentado, mais próxima do que James chamou de familiaridade com, a exemplo do fluxo constante das notícias de televisão e de notícias digitais que livre e constantemente oferecem impressões, mas pouco oferecem em termos de estrutura narrativa e relações. Chamamos esse primeiro tipo de notícias-comoimpressões. Uma outra parte desse universo segue reconhecidamente semelhante ao que Park analisou na metade do século XX, ainda que alguns aspectos identificados por ele tenham se intensificado. Essas são as notícias-como-itens, que se apresentam na forma de matérias e publicações particulares, com características que já associamos à notícia. Por fim, e simultaneamente, a ascensão de combinações de jornalismos long-form, explicativo e de dados, que ultrapassam a manchete e as matérias, sugerem que algumas formas de notícias oferecem, cada vez mais, um saber próximo do conhecimento sobre do qual James falou, mas, ainda assim, são reconhecidas como notícias, com base parcialmente no trabalho da reportagem in loco e a partir de testemunhos, e são mais oportunas do que, por exemplo, as humanidades e as ciências sociais como outras formas de conhecimento sobre assuntos atuais. Podemos chamá-las de notícias-sobre-relações. As notícias continuam a fornecer o 
primeiro rascunho da história, mas agora esse rascunho vem cada vez mais de diferentes formas, variando das impressões instantâneas rabiscadas e compartilhadas em fluxos até as formas mais detalhadas, guiadas por dados e sistemáticas de jornalismo explicativo, que vão muito além das notícias que eram oferecidas no século XX.

Parte desse desenvolvimento - de notícias como forma de conhecimento entre a familiaridade com e o conhecimento sobre no século XX para notícias digitais como formas de conhecimento mais diferenciadas, incluindo maior familiaridade com, mas também maior conhecimento sobre - diz respeito à inovação profissional e à ambição jornalística associadas a pioneiros como Jonah Peretti, do Buzzfeed, e Melissa Bell, do Vox Media, assim como ao pensamento evolutivo de marcas estabelecidas como CNN e New York Times. Não apenas o jornalismo rápido, mas também o slow journalism ${ }^{10}$ vem sendo integrado às práticas profissionais e aos fluxos de trabalho das redações, assim como se tem evitado produzir conteúdo longo demais para ser compartilhado e curto demais para ser considerado uma produção em profundidade. Em um nível fundamental, o jornalismo também é guiado pelo desenvolvimento de sistemas tecnológicos maiores, ligados ao modo como as notícias são produzidas e publicadas. Essa questão é destacada por Sloan (2010) em sua referência aos mecanismos de busca e dá suporte para questionar se a notícia é transitória e efêmera e de que maneira ela seria assim. Em termos de conteúdo informativo, muitas notícias digitais podem ser transitórias. Porém, em relação à mediação e à disponibilidade, muitas são cada vez menos efêmeras por causa da combinação entre publicação digital e desenvolvimento de mecanismos de buscas, a exemplo do Google. 0 pesquisador Lev Manovich compreendeu muitos desses aspectos-chave desde cedo. Em 2001, ele destacou cinco tendências de "uma cultura em fase de informatização" (MANOVICH, 2001, p. 27):

1. Representação numérica: a existência de objetos da nova mídia, como os dados.

2. Modularidade: os diferentes elementos da nova mídia existem independentemente.

3. Automação: os objetos da nova mídia podem ser criados e modificados automaticamente.

4. Variabilidade: a existência de objetos da nova mídia em múltiplas versões.

5. Transcodificação: a lógica do computador influencia como nós entendemos e representamos nós mesmos.

\footnotetext{
${ }^{10}$ Nota das tradutoras: o termo slow journalism, que não costuma ser traduzido para o português, está relacionado ao tempo de produção jornalística e a movimentos como slow food (em oposição ao fast food) e foi usado por Susan Greenberg pela primeira vez em 2007. Busca caracterizar artigos, reportagens e outros tipos de escrita de não ficção que levam mais tempo para serem produzidos, ao contrário das notícias de última hora.
} 
Todos esses desenvolvimentos podem ser observados nas notícias, que são transformadas em dados digitais no processo de produção e uso. Esses dados podem ser agregados, compartilhados e recombinados e cada vez mais podem ser vistos pelas lentes culturais das tecnologias que permitem seu uso em novas formas digitais. Em um texto anterior, Manovich (1999) destacou como a internet privilegia as bases de dados em detrimento das narrativas, um prenúncio de como os mecanismos de busca nos ajudam a navegar na Web a partir de padrões de links e ranqueamento de páginas em vez de princípios semânticos. Na análise do autor, esse desenvolvimento representa uma inversão básica na relação entre sintagma e paradigma, partindo de uma situação em que a navegação pela narrativa e pela base de dados estava implícita para se chegar a uma situação em que o paradigma da base de dados é central e o sintagma (a narrativa) é menos importante. Isso se deve em parte à representação numérica do conteúdo de mídia (como dados digitais) e à sua modularidade (elementos independentes uns dos outros), que podemos encontrar nas notícias de diferentes maneiras, por meio de novos e cada vez mais importantes intermediários digitais, como os mecanismos de busca e as mídias sociais (BELL, 2014; DIJCK, 2013). Nenhum dado sistemático está disponível publicamente, mas conversas com editores digitais sugerem não apenas que os mecanismos de busca e as mídias sociais representam grande parte do tráfego total do consumo de notícias na Web, mas também que os acessos diretos à capa do site, com tráfego originário de buscas e de mídias sociais, exibem diferentes e interessantes orientações temporais, com o tráfego da capa do site guiado pelas atualizações, pelo tráfego a partir das buscas por postagens antigas e pela distribuição, pelas mídias sociais, de conteúdos recentes, mas não de última hora.

No nível mais básico, a descrição de Manovich $(1999 ; 2001)$ das características da ascensão da mídia digital significa que conteúdos noticiosos altamente transitórios não são mais tão efêmeros em termos de acesso. Busque na Web por praticamente qualquer tópico e você encontrará notícias, às vezes antigas, provenientes de veículos de comunicação fortemente visíveis ao redor do mundo. Clique nos links compartilhados via mídias sociais a respeito de assuntos atuais e eles vão levá-lo a um contexto histórico, não somente às notícias de última hora. As empresas de mídia estão cada vez mais cientes disso e - em consonância com o que o autor observa sobre o modo como a mídia digital influencia como entendemos o que fazemos e como apresentamos o que fazemos ao mundo - estão tentando operar a partir de novas e diferentes formas de distribuição e criação de conteúdo, promovendo seus arquivos (às vezes de décadas ou séculos atrás), priorizando medidas 
para incrementar a validade de conteúdo novo e utilizando várias ferramentas de tecnologia para guiar os leitores de uma matéria para a outra (independentemente de o conteúdo ser antigo ou recente). Trata-se de uma nova forma de encontrar, experienciar e explorar as notícias - uma transformação que permite que a maioria de nós possa se conectar com as notícias. Esse desenvolvimento ainda está em estágio inicial, a exemplo das limitações dos mecanismos de busca e da navegação pelas bases de dados e do fato de que os custos de armazenamento e transmissão, embora em declínio, ainda fazem priorizar o conteúdo textual em detrimento das imagens, do áudio e do vídeo em termos de encontro, recuperação e visibilidade. Tudo isso aponta para um futuro em que muito do que é publicado como notícia nunca precisa desaparecer - a não ser que alguém queira que isso desapareça, mantenha isso em bancos de dados privados ou seja forçado a criar algo difícil de encontrar, como no caso do "Direito ao Esquecimento", decisão da Corte de Justiça Europeia contra o Google em 2014.

\section{Um novo capítulo na Sociologia do Conhecimento?}

As notícias digitais, por conta das mudanças nas práticas sociais, nos modos de organização e nas tecnologias de mídia que criam e constituem essas notícias, representam uma variedade de formas de conhecimento na atualidade. Muitos dos aspectos-chave que apareceram na análise de Robert E. Park em 1940 ainda podem ser encontrados nas notícias - elas são orientadas para eventos em vez dos processos, raramente lidam sistematicamente com causalidade ou teleologia e o conteúdo é geralmente transitório. Porém, hoje é preciso considerar que as notícias são algo cuja diversidade é crescente e que muitas delas estão longe de serem efêmeras.

Algumas formas de notícias digitais - pelo volume, provavelmente a maior parte dessas notícias - ainda podem estar avançando em direção à familiaridade com do início do continuum das formas de conhecimento de William James, oferecendo impressões mediadas sobre as coisas do mundo além da nossa experiência imediata, mas rendendo pouco em termos de situar tais eventos em relação a processos mais amplos sobre o que acontece e o seu significado. Tais fluxos de notícia são produzidos por organizações de mídia digital, como por exemplo o Buzzfeed, mas certamente também por veículos tradicionais e de referência, como a CNN (no ar e online) e o New York Times (por meio do Times Wire, das 
contas de Twitter, dos avisos de manchete nos smartwatches etc.). Muitos críticos depreciam tais formas de notícias, alguns por boas razões.

Esse desenvolvimento, porém, não deveria nos cegar em relação ao crescimento paralelo e simultâneo de formas digitais de notícia que estão muito próximas do conhecimento sobre do final do continuum de James, como os jornalismos long-form, explicativo e guiado por dados, que oferecem notícias mediadas e disponíveis publicamente, que estão preocupadas com questões de causalidade, teleologia e de relações entre os eventos e que oferecem tudo isso de uma forma mais acessível e moderna do que outras formas de conhecimento sobre assuntos atuais. Organizações de mídia de referência, como a CNN e o New York Times, investem recursos significativos na produção de investigações em profundidade, detalhadas e duradouras. Sites como o Buzzfeed também têm criado equipes de jornalismo investigativo nos Estados Unidos e no Reino Unido, nos últimos anos.

Esses tipos mais variados de notícias digitais, que sugiro pensar como notíciascomo-impressões, notícias-como-itens e notícias-sobre-relações, também são formas importantes e menos transitórias e efêmeras do que as notícias analisadas por Park (1940). Isso se deve, em parte, ao caráter temporal do conteúdo produzido: a orientação temporal das notícias-como-impressões é geralmente o "agora" e a das notícias-como-itens é aproximadamente as últimas 24 horas (o que associamos aos jornais e telejornais), mas, nas notícias-sobre-relações, esse período é geralmente muito maior e quebra com o ciclo acelerado de notícias em favor de algo mais durável. Essa mudança também se deve à tecnologia, ao conteúdo digital e online publicado pelos veículos de comunicação e ao fato de que hoje as notícias podem ser acessadas por meio de uma grande variedade de consultas a bancos de dados, mecanismos de busca e mídias sociais que nos oferecem novas formas de engajamento com as notícias, incluindo as de ontem e as do ano passado (formas de engajamento especialmente importantes para tipos de notícias criadas para serem menos transitórias e efêmeras).

Essas mudanças nas notícias como conhecimento parecem ser dignas de um novo capítulo na Sociologia do Conhecimento e de uma apreciação das muitas formas de conhecimento que as notícias oferecem à maioria das pessoas hoje. É claro que, para entender as implicações dessa mudança, as notícias digitais como formas de conhecimento precisam ser entendidas em relação às diferentes autocompreensões, concepções populares, hipóteses acadêmicas e teorias normativas que existem sobre o tema. A evidência até o momento sugere que, mesmo que as notícias se tornem mais diversas e sejam acessadas a 
partir de práticas mais amplas de consumo de mídia - uma olhada rápida no celular na parada de ônibus, como parte do feed das mídias sociais -, a maioria das pessoas ainda vê a categoria das "notícias" como algo significante e distante do contexto mais amplo de "notícias para mim". No entanto, o modo como as pessoas navegam nas notícias, disponíveis em um cenário de oferta abundante, destaca a grande importância de entender a mudança de relação entre a produção de notícias (incluindo a autocompreensão jornalística) e o uso das notícias (concepções populares, o significado social da notícia, a motivação para o uso etc.) (BOCZKOWSKI; MITCHELSTEIN, 2010; NEUMAN; PARK; PANEK, 2012; PRIOR, 2007). Como Alex Madrigal (2013) notou, as questões que podemos enfrentar incluem como os produtores de conteúdo se posicionam entre o que as pessoas na indústria de mídia chamam de "estoque" e "fluxo", como diferentes intermediários facilitam o estoque e o fluxo e oferecem formas de lidar com cada um deles e, finalmente, como os usuários combinam estoque e fluxo. A oferta das notícias-como-impressões, notícias-como-itens e notíciassobre-relações é importante, assim como a demanda por elas. Os pioneiros nas notícias digitais estão altamente conscientes dessas diferenças e estão experimentando novas formas de fazer jornalismo, que alavancam as vantagens de cada uma das formas para diferentes propósitos editoriais - além de comerciais e outros.

Para os acadêmicos preocupados com o impacto das notícias em relação ao que as pessoas sabem, o desenvolvimento das notícias digitais desafia o desenho teórico e metodológico de maneiras interessantes (BENNETT; IYENGAR, 2008). Consideremos três das mais importantes formas de estudar a relação entre as notícias e o conhecimento pesquisas de survey, pesquisas experimentais e análise de conteúdo. A pesquisa de survey, que depende de dados autorrelatados sobre a exposição à mídia, é boa para muitas coisas, mas não necessariamente captura o impacto de um vídeo de seis segundos do Vine ou de uma publicação jornalística detalhada e interativa. Pesquisas experimentais com configurações controladas podem nos trazer um melhor entendimento da importância de variações no conteúdo e nas formas de notícia, mas cada vez mais encontram problemas de validação externa e, assim, a generalização sobre o uso das notícias se torna uma prática menos distinta e o conteúdo das notícias se torna uma categoria mais diversa e fluida. A análise de conteúdo, desenvolvida para análise das notícias-como-itens, também encontra desafios quando se trata de programar grandes volumes de notícias-como-impressões e formas mais caras de notícias-sobre-relações que vão além da publicação individual de um texto jornalístico. São desafios que se tornarão maiores quando as empresas de 
comunicação começarem a usar formas mais responsivas de design e a aproveitar o potencial da automatização na personalização de textos, imagens e vídeos para audiências diferentes.

Não é propriamente surpreendente ou inusitado dizer que as notícias têm mudado também em termos de sua relação com o conhecimento nos últimos 75 anos. As notícias são um fenômeno histórico, que mudam ao longo do tempo, assim como são um fenômeno social e contextual que varia através do espaço. Mas quero destacar dois pontos que atravessam este texto. Primeiro, Robert E. Park continua sendo um comentarista perspicaz sobre a relação entre a notícia e o conhecimento, sobre a característica (sob mudança) da notícia como algo que "não só informa, mas também orienta o público, mostrando o que está acontecendo", de modo que sua análise de 1940 continua a captar certos aspectos-chave em relação à informação mediada e publicamente disponível na forma de notícia em comparação com outras formas de conhecimento. Segundo, embora o ambiente de mídia de Park fosse igualmente complexo e diverso, o nosso ambiente de mídia, hoje, é certamente mais complexo e diverso, e a ideia da notícia como forma de conhecimento deveria ser substituída pela ideia de notícia como formas de conhecimento, para pensar o quanto a complexidade do ambiente midiático está empurrando a notícia para os extremos da familiaridade com (notícias-como-impressões) e do conhecimento sobre (notícias-sobrerelações) e pode até mesmo fazer erodir o entendimento de Park de que as notícias de jornal, rádio e televisão (as notícias-como-itens, como as trazemos do século XX) estariam no meio do continuum.

\section{Referências}

BARNHURST, Kevin G.; MUTZ, Diana. American Journalism and the Decline in EventCentered Reporting. Journal of Communication, [s.l.] v. 47, n. 4, 1997, p. 27-53. doi:10.1111/j.1460-2466.1997.tb02724.x.

BARNOUW, Erik. The Golden Web: A History of Broadcasting in the United States - 1933 to 1953. New York: Oxford University Press, 1968. v. 2.

BELL, Emily. Silicon Valley and Journalism: Make up or Break Up? Presented at the Reuters Memorial Lecture 2015, Reuters Institute for the Study of Journalism, Oxford, 21 nov. 2014. 
BENNETT, W. Lance; IYENGAR, Shanto. A New Era of Minimal Effects? The Changing Foundations of Political Communication. Journal of Communication, [s.l.], v. 58, n. 4, 2008, p. 707-31.

BOCZKOWSKI, Pablo J.; MITCHELSTEIN. Eugenia. Is There a Gap between the News Choices of Journalists and Consumers? A Relational and Dynamic Approach. The International Journal of Press/Politics, [s.l.], v. 15, n. 4, 2010, p. 420-40. doi:10.1177/1940161210374646.

CRAIG, Douglas B. Fireside Politics: Radio and Political Culture in the United States, 19201940. Baltimor: Johns Hopkins University Press, 2000.

DIJCK, José van. The Culture of Connectivity: A Critical History of Social Media. Oxford: Oxford University Press, 2013.

ESHBAUGH-SOHA, Matthew; PEAKE, Jeffrey S. Breaking through the Noise: Presidential Leadership, Public Opinion, and the News Media. Stanford: Stanford University Press, 2011.

ETTEMA, James S.; GLASSER, Theodore Lewis. Custodians of Conscience: Investigative Journalism and Public Virtue. New York: Columbia University Press, 1998.

FALLOWS, James. Learning to love the (shallow, divisive, unreliable) new media. The Atlantic, [S.l.], 2011. Disponível em:

https://www.theatlantic.com/magazine/archive/2011/04/learning-to-love-the-shallowdivisive-unreliable-new-media/308415/. Acesso em: 15 ago. 2020.

FEDERAL COMMUNICATIONS COMMISSION. Broadcast station totals as of december 31, 2014. Washington D.C.: FCC, 2015. Disponível em:

https://docs.fcc.gov/public/attachments/DOC-331381A1.pdf. Acesso em: 15 ago. 2020.

FENTON, Natalie (org.). New Media, Old News: Journalism \& Democracy in the Digital Age. London: Sage, 2010.

FINK, Katherine; SCHUDSON, Michael. The Rise of Contextual Journalism, 1950s-2000s. Journalism, London, v. 15, n. 1, 2014, p. 3-20. doi:10.1177/1464884913479015.

GANS, Herbert J. Popular Culture and High Culture: An Analysis and Evaluation of Taste. New York: Basic Books, 1974.

GITLIN, Todd. Media Unlimited: How the Torrent of Images and Sounds Overwhelms Our Lives. New York: Metropolitan Books, 2001.

GRAVES, Lucas. Deciding What's True: The Fact-Checking Movement in American Journalism. New York: Columbia University Press, 2016.

GREENBERG, Susan. Slow journalism: why doesn't Britain have a culture of serious nonfiction journalism like the US? Prospect, [s.l.], 25 feb. 2007. Disponível em: https://www.prospectmagazine.co.uk/magazine/slowjournalism. Acesso em: 14 ago. 2019. 
HERMIDA, Alfred. Twittering the News. Journalism Practice, London, v. 4, n. 3, 2010, p. 297-308. doi:10.1080/17512781003640703.

JAMES, William. The Principles of Psychology. New York: Henry Holt, 1890.

LONGHI, Raquel Ritter; WINQUES, Kérley. O lugar do longform no jornalismo online: qualidade versus quantidade e algumas considerações sobre o consusmo. Brazilian Journalism Research, V. 1, N. 1, p. 110-127, 2015.

MADRIGAL, Alexis C. 2013: The Year "the Stream" Crested: the stream is fun and fast, but don't you miss the sense of an ending?. The Atlantic, [s.l.], 12 Dec. 2013.

MANOVICH, Lev. The Language of New Media. Cambridge: MIT Press, 2001.

MANOVICH, Lev. New Media: A User's Guide. Manovich, [s.l.], 1999.

MIELNICZUK, Luciana. Jornalismo na Web: uma contribuição para o estudo do formato da notícia na escrita hipertextual. Tese (Doutorado em Comunicação e Cultura Contemporâneas), Faculdade de Comunicação, Universidade Federal da Bahia, Salvador, 2003.

MITCHELL, Amy; PAGE, Dana. The growth in digital reporting: what it means for journalism and news consumers. Washington D.C.: Pew Research Center, 2014. Disponível em: https://www.journalism.org/wp-content/uploads/sites/8/2014/03/Shiftsin-Reporting_For-uploading.pdf. Acesso em: 15 ago. 2020.

NEUMAN, W. Russell; PARK, Yong Jin; PANEK, Elliot. Tracking the Flow of Information into the Home: An Empirical Assessment of the Digital Revolution in the U.S. from 1960-2005. International Journal of Communication, Los Angeles, n. 6, 2012, p. 1022-41.

NEWMAN, Nic. Media, journalism and technology predictions 2015. Oxford: Reuters Institute for the Study of Journalism, 2015. Disponível em:

https://reutersinstitute.politics.ox.ac.uk/risj-review/media-journalism-and-technologypredictions-2015. Acesso em: 15 ago 2020.

NEWS MEDIA ALLIANCE. Website. Arlington: News Media Alliance, 2020. Disponível em: https://www.newsmediaalliance.org/. Acesso em 10 ago. 2020.

NIELSEN SOCIAL. $\mathbf{3 1 . 7}$ million viewers tune in to watch pres. Obama's state of the union address. [S.l.], 2015. Disponível em:

https://www.nielsen.com/us/en/insights/article/2015/31-7-million-viewers-tune-in-towatch-pres-obamas-state-of-the-union-adress/. Acesso em: 15 ago. 2020.

OBAMA, Barack. Remarks by the President at a "Moving America Forward" Town Hall. The Office of the Press Secretary. Washington D.C.: The White House, 2010. Disponível em: https://obamawhitehouse.archives.gov/the-press-office/2010/10/12/remarks-presidenta-moving-america-forward-town-hall. Acesso em: 15 ago. 2020. 
PARK, Robert E. News as a Form of Knowledge: A Chapter in the Sociology of Knowledge. American Journal of Sociology, Chicago, v. 45, n. 5, 1940, p. 669-686.

PRIOR, Markus. Post-Broadcast Democracy: How Media Choice Increases Inequality in Political Involvement and Polarizes Elections. New York: Cambridge University Press, 2007.

PRIEST, Dana; ARKIN, William M. Top secret America: the rise of the new american security state. New York: Little, Brown and Company, 2011.

SCHONFELD, Erick. Jump into the Stream. [S.I]: Techcrunch, 2009. Disponível em: http://techcrunch.com/2009/05/17/jump-into-the-stream/. Acesso em 15 ago. 2020.

SHIBUTANI, Tamotsu. Improvised News: A Sociological Study of Rumor. Indianapolis: Bobbs-Merrill, 1966.

SLOAN, Robin. Stack and flow. [S.l.], Snarkmarket, 2010. Disponível em: http://snarkmarket.com/2010/4890. Acesso em 15 ago. 2020.

THOMPSON, Derek. The Unbearable Lightness of Tweeting'. The Atlantic, [s.l.], 16 Feb. 2015.

TUCHMAN, Gaye. Making News: A Study in the Construction of Reality. New York: Free Press, 1978.

WEBSTER, James G. The Marketplace of Attention: How Audiences Take Shape in a Digital Age. Cambridge: The MIT Press, 2014.

\title{
Digital news as forms of knowledge: a new chapter in the Sociology of Knowledge
}

\begin{abstract}
This paper, originally published as a book chapter, discusses the forms of knowledge generated by digital news and it is a revision of what Robert Park proposes in his article News as a form of knowledge, from 1940. Park has located informative journalism somewhere in the continuum between "acquaintance with" and "knowledge about", and this study goes a step further, proposing three ideal-typical forms of news produced and consumed today in digital environments: news-as-impression, news-as-items and news-about-relations. These categories are proposed and used to describe and to try to understand the more ephemeral or contextual character of the news. This paper advocates, at last, that digital news produces not only one form of knowledge, but different forms of knowledge.
\end{abstract}




\section{Keywords}

Journalism. Digital journalism. News. Sociology of Knowledge.

Robert Park.

\section{Autor correspondente}

Anelise Schütz Dias

anelisesdias@gmail.com

\section{Como citar}

NIELSEN, Rasmus Klein. Notícias digitais como formas de conhecimento: um novo capítulo na Sociologia do Conhecimento. Tradução: Marcia Benetti, Anelise Schütz Dias, Marília Gehrke. Intexto, Porto Alegre, n. 52, e-96916, jan./dez. 2021. DOI: http://dx.doi.org/10.19132/1807-8583202152.96916

Recebido em 28/09/2019

Aceito em 18/02/2020 